\title{
A PONTUAÇÃO $\in$ AS CULTURAS DA ESCRITA
}

Véronique Dahlet

RESUMO: Esta contribuição procura mostrar como a página, quando conseguiu remeter a si mesma pelo fato de se constituir como suporte e espaço da escrita, liberou o pensamento da percepção imediata do mundo, proporcionando a criação de seus próprios métodos de desenvolvimento, que se tornaram auto-suficientes. Essa profunda transformação ocorreu mediante o aperfeiçoamento dos processos materiais de apresentação da escrita e, manifestamente, via segmentação paragráfica e pontuação. Ora, percebe-se um paradoxo persistente, o qual consiste em reconhecer a superfície concreta da página, isto é, o branco, sem, entretanto, desistir de Associar a fala escrita à voz, que seria registrada principalmente pelos sinais de pontuação.

PALAVRAS-CHAVE: Pontuação; Parágrafo; Branco; Voz; Cultura(s) da escrita.

o observar o momento em que a fala pôde se afastar da voz e, junto com ela, do corpo de quem fala; ao observar algumas etapas decisivas que levaram os técnicos e letrados a inserir no sistema alfabético um outro sistema, ideográfico, tal como conhecemos a pontuação hoje, vamos descobrir que a pontuação foi objeto de um paradoxo, que permanece ainda, cuja questão central gira em torno dos conceitos de oral e de escrito. Outro paradoxo, decorrente

\footnotetext{
Universidade de São Paulo.

O texto aqui publicado foi apresentado no formato de uma aula, ministrada como um dos requisitos para obtenção do título de professor titular do Departamento de Letras Modernas da Faculdade de Filosofia, Letras e Ciências Humanas, em 16/11/2006.)
} 
DAHLET, Véronique. A pontuação e as culturas da escrita.

possivelmente do precedente: a rivalidade contínua, o conflito incessante, entre, por um lado, a pontuação e o espaço gráfico que a manifesta, e, por outro, a voz e o corpo pressuposto por esta última. A análise dos sinais de citação apontará para casos que discutem o oral veiculado pela pontuação. Enfim, abordaremos dois momentos da poesia e da literatura (fim do século XIX e século XX) que chamaram muito minha atenção pelo fato de eles irem, via pontuação e exploração da página, à revelia dos valores históricos que constituíam seus respectivos contextos de criação.

\section{I - O BRANCO CONTRA A VOZ}

\section{1-1. Um "modo de pensamento constituinte"}

A invenção da escrita, que pode ser associada ao avanço do branco em detrimento da voz, abriu a possibilidade de se comunicar mediante um objeto que prescinde o face a face e acarretou transformações profundas. Com efeito, as "mudanças de meios e de modo de comunicação" não afetaram somente as "maneiras de entender o mundo em geral" (Goody, 1993), mas também produziram, ao longo do tempo, novas atividades cognitivas. Assim, para Leibniz, segundo Anis (1988, p. 30), a

escrita não é mais um mero veículo do pensamento, um artifício técnico, mas um modo de pensamento constituinte [grifo meu].

Além disso, a escrita resulta numa fabricação de um objeto, o livro, cuja própria concretude direciona a construção do sentido (Jacob, 2000, p. 54):

A materialidade do livro e as exigências de seu manejo afetam as modalidades de apropriação do texto, o processo de construção do sentido.

A invenção do livro, essa "encarnacão do texto numa materialidade específica" (no dizer de Roger Chartier), provocou o deslocamento do oral para o visual. Essa transformação radical levou 
séculos, já que o visual se caracteriza por propriedades a priori, absolutamente contrárias ao oral. De fato, esse distanciamento que se verifica nas características do visual em relação às do oral segue as etapas da invenção do livro, que associarei à busca dos suportes cada vez mais suscetíveis de melhorar a fixação escrita da linguagem.

Grosso modo, podemos distinguir duas fases do suporte (excetuada a argila, que provém da região de Suméria, lugar em que nasceu a escrita):

a) Antes do século II a.C., o escrito se apresentava sob forma de rolo, de volumen. A morfologia do rolo apresentava o defeito de impossibilitar a prática simultânea da escrita e da leitura, já que era preciso segurá-lo com as duas mãos.

b) a partir do século II d.C., o rolo de papiro foi suplantado pelo códice latino, de pergaminho (Araújo, 1986, p. 414; Ken Morrison, 1995, p. 146). O códice traz uma revolução na sua apresentação, com a invenção da página, que muda o eixo da escrita para o sentido horizontal, tornando-se verdadeiramente superfície (pois o rolo proporcionava apenas um desfile de colunas, o que o adequava à sua função de "suporte da memória" (Zali, 1999, p. 37). A página, que significa seção em latim, como lembra Araújo (1986, p. 414), instaura, portanto, o descontínuo, uma unidade visual autônoma, e interina o início da longa "gênese da abstração" (Bottéro, 1995). A meu ver, a noção central que merece destaque é a de descontínuo, pois permitirá ultrapassar a atividade de simples consignação dos bens, como permitirá, também, dissociar-se da ordem do mundo para aportar na ordem da elaboração abstrata. Nessa perspectiva, a invenção da página, que terá, no dizer de R. Chartier (1996, p. 33), "uma influência considerável sobre o desenvolvimento intelectual", ${ }^{1}$ construirá

Além disso, a passagem do volumen para o códex traduz uma visão diferente do mundo (Souchier, 1996, p. 39). Com efeito, para os gregos, o delinear do tempo é cíclico, e não retilíneo, de tal modo que a concepção mitológica do tempo, com o fluxo dos ciclos, se 
DAHLET, Véronique. A pontuação e as culturas da escrita.

aos poucos uma lógica da tabularidade que completará o sistema da linearidade da escrita, no intuito de melhor responder às necessidades editorias das scriptórias (aprimoramento dos sistemas remissivos das cópias entre si, redução dos riscos de apócrifos), bem como às necessidades das leituras escolásticas.

\section{1-2. A paragrafação}

Nessa perspectiva, a história da paragrafação é exemplar, pois mostra as determinações que regem sua função, que é diretamente ligada às condições concretas de leitura. Essas condições concretas explicam a razão pela qual o parágrafo é o primeiro sinal de pontuação que apareceu nos textos, pois a ordem tabular, isto é, a introdução de marcas divisórias da escrita que permitiam ao escriba ou ao leitor referir-se diretamente a blocos textuais sem obrigação de retomar o texto desde seu início, respondia a uma necessidade prioritária em relação à segmentação de unidades textuais menores, seja a unidade frasal ou interna à frase.

Várias foram as marcas de segmentação da escrita em blocos, mas, seja qual for a aparência da segmentação, o fato digno de nota remete à necessidade cada vez mais imperiosa de dar uma arquitetura ao texto, ${ }^{2}$ o que confirmaria, caso fosse necessário, a função primeira e fundamental de legibilidade.

A aparição significativa do parágrafo é o resultado de uma dupla conjuntura: por um lado, deve-se à passagem da lectio para a divisio e, por outro, às necessidades de harmonizar as referências tanto nas cópias da Bíblia quanto nos livros de comentários a respeito.

acorda melhor com o volumen. Já, para os cristãos, a visão teológica da história encontra a visão orientada do códex, cuja leitura tende para o fim: fim da linha, fim da página, fim do livro. "Como se a energia da leitura estivesse, no códex, orientada para a revelação prometida do 'Livro de Vida' do Apocalipse" (Souchier, 1996, p. 39). Cf. também Ivan Illich (1991).

2 As várias etapas de estabelecimento do parágrafo se estendem do século VII ao século XIV. 
Filol. lingüíst. port., n. 8, p. 287-314, 2006.

(a) A passagem da lectio para a divisio remete à renovação do método de ensino, para o qual a separação do texto em partes nitidamente delimitadas tornou-se crucial. Com efeito, se a leitura dos textos, a lectio, centrava-se no comentário de cada frase, uma depois da outra (textos de teologia, de direito, de artes liberais), a leitura na época escolástica vem se centrar na técnica da divisão (a divisio), doravante aplicada tanto no ensino quanto no estudo individual. ${ }^{3}$ Assim como lembra Châtillon (1985) e Ivan Illich (1991), legere nessa época significa ler, mas também ensinar: ex-plicare (literalmente desdobrar) consiste em trazer à luz o sentido escondido (leitura), mas também consiste em ensinar segundo uma determinada ordem, uma estrutura articulada, singularmente, ex-plicada. Vale acrescentar o fato de que o desdobrar se realizava quase sempre através de comentários, que, contíguos ao texto comentado, ocupavam o mesmo espaço da página.

(b) Paralelamente a essa profunda mudança na apreensão dos textos, a Bíblia, cujos comentários constituíam a maior parte do ensino, em seus vários livros, oferecia, ora textos compactos sem divisão, ora textos divididos em capítulos, porém, nesse caso, o lugar da divisão não coincidia de um manuscrito para outro.

No fim do século XII, uma nova divisão em capítulos da Bíblia para a totalidade de seus livros foi aos poucos aceita e veio se generalizando para as cópias ulteriores. Enfim, no século XVI, foi introduzida a divisão em breves estrofes, assim como ainda permanece hoje em dia. ${ }^{4}$

Por último, apareceu a alínea, que é, morfologicamente falando, um branco, um vazio. A alínea foi introduzida pela imprensa e, se pensarmos bem, esse fato não é casual. De fato, tratou-se de

Hugues de Saint-Victor (século XII) escreve no seu tratado Didascalion: "Lire, c'est diviser": Ler consiste em dividir. Cf. Illich, 1991.

4 Para mais detalhes, remeto ao artigo de Châtillon (1985), do qual emprestei essas informações. 
DAHLET, Véronique. A pontuação e as culturas da escrita.

substituir algo cheio - o sinal de $[\S]$ - pelo vazio, pelo branco. Ora, como nota com perspicácia Marc Arabyan (1994),”o branco é o que é mais escrito", no sentido de que fazer significar o branco consiste em se apoiar totalmente, de maneira absoluta, ao suporte. Sem dúvida, essa troca do cheio para o vazio é emblemática, para retomar R. Laufer (1985, p. 62), da

transformação de um sistema de referência para uma técnica de escrita auto-referente que constitui a transformação decisiva da mentalidade. (Tradução minha $)^{5}$

Essa transformação decisiva consiste, a meu ver, na consagração da auto-suficiência da escrita a remeter a si mesma e a estruturar seus conteúdos sem outro recurso que a própria materialidade da página, no caso, o branco. ${ }^{6}$

Entretanto, a arqueologia do parágrafo constituiu o preâmbulo à conceituação da pontuação, dessa vez em nível da frase.

\section{1-3. Estados da pontuação}

Foi sob o efeito da imprensa que a pontuação veio se formalizando, se regulando. Entretanto, esse longo trabalho de racionalização e de regulamento do emprego dos sinais conheceu seu auge no século XIX, sob o efeito de dois fenômenos principalmente. Em primeiro lugar, reinava uma certa anarquia no modo como os editores pontuavam os textos dos autores que publicavam, enquanto o setor de difusão editorial e jornalística se desenvolvia de maneira

\footnotetext{
“Transformation d'un système de repérage en une technique d'écriture auto-repérante qui constitue la transformatoin décisive de la mentalité"

6 Laufer ("Lalinéa typographique du XVle au XVIIIe siècle", 1985, p. 54) considera que a imprensa mudou profundamente as regras de escrita e, ao perguntar-se qual é a ligação entre as condições técnicas da comunicação e a elaboração do pensamento, chega a dizer que a enunciação escrita tornou-se uma enunciação tipográfica.
} 
exponencial. Em segundo lugar, a escola, obrigatória a partir do fim do século XIX (em 1880, na França), começou a formar leitores em massa. Nesse contexto geral, uma maior racionalização da pontuação se tornou urgente e crucial.

Coube aos gramáticos descrever, justificar e regulamentar os usos certos dos sinais de pontuação. Século após século, de uma gramática para outra, encontram-se infalivelmente os três critériosmestres capazes de dar contar e de justificar a ocorrência dos sinais de pontuação. São eles: a sintaxe, o semantismo e a voz, via entonação e pausas. Se a sintaxe e o semantismo correspondem claramente a funções da pontuação, nada, em contrapartida, sustenta objetivamente o critério da reprodução, até mesmo aproximativa, da voz. Veremos mais adiante em que consiste essa visão epistemológica, de que ela procede, para, num primeiro momento, ater-me às funções da pontuação.

A razão primeira da pontuação é a de dotar a linguagem escrita de uma legibilidade máxima. Essa legibilidade, entretanto, foi se elaborando mediante duas funções maiores. Contrariamente à metodologia das gramáticas, que opta por apresentar os sinais e suas funções mediante uma mera nomenclatura, parece-me de grande valia relacionar de antemão os sinais às suas respectivas funções, para oferecer de imediato uma visão estruturante e arrazoada da pontuação. Por isso, convém dividir o repertório dos sinais em duas classes (Dahlet, 2006). [Doc.1]

A. A primeira classe será chamada de sinais de sequencialização por operar em nível sintagmático. Ou seja, essa pontuação corta o contínuo linear da escrita, criando segmentos determinados por parâmetros sintáticos, semânticos e discursivos. De modo que os sinais de sequiencialização abrangem a alínea, o ponto, assim como seus variantes (pontos de exclamação e de interrogação, reticências), o ponto-vírgula e, enfim, a vírgula.

B. A segunda classe será chamada de sinais de enunciação, por eles manifestarem um tipo de interação com o co-enunciador. 
DAHLET, Véronique. A pontuação e as culturas da escrita.

No intuito de analisar adequadamente esse grupo de sinais de enunciação, é indispensável dividi-lo em duas partes, segundo o cotexto em que eles ocorrem. Com efeito, estes últimos não possuem a mesma função quando ocorrem num cotexto monologal ou num dialogal. A distinção entre ambos os cotextos é formal, e conviremos caracterizar o cotexto monologal por ser assumido formalmente por um só locutor, ao passo que o cotexto dialogal dá lugar ao interdiscurso, fazendo coexistir formalmente duas falas. Dois exemplos serão suficientes para ilustrar a pertinência dessa distinção:

(a) as aspas, em cotexto monologal, adquirem valor autonímico, e valor de citação em cotexto dialogal;

(b) as reticências, em cotexto monologal, criam um palco para uma interação, entre os co-enunciadores (quem escreve e quem lê), ao passo que, em cotexto dialogal, elas criam um palco para a encenação de uma interação, indicando a interrupção do Locutor 1 pelo Locutor 2.

\section{A VOZ, APESAR DO BRANCO}

Vimos que o conceito de página nasceu com o códice (ou có$d e x$ ), que conseguiu se impor de maneira definitiva. De fato, o conceito de página, enquanto unidade material, veio a adquirir um grau de "evidência" plena, de modo que faltava pouco para associar a unidade do pensamento à unidade da página. Entretanto, a concretude do suporte material não impediu a representação segundo a qual a escrita transcreve a fala. A escrita seria, portanto, a imagem incorporada - via gesto da inscrição - da vosz, a transcrição da fala. Ou seja, com a invenção da escrita, a disjunção da voz/do corpo e da escrita foi de fato acabada, mas não no plano das representações. Assim, da mesma maneira que os grafemas são supostamente encarregados de reproduzir os fonemas da língua oral, coube à pontuação a função de dar conta, mesmo que de maneira im- 
Filol. lingüíst. port., n. 8, p. 287-314, 2006.

perfeita, das características da voz - entonação, cadência, pausas, ritmo.

O que poderia explicar essa resistência, no plano das representações? De minha parte, vejo principalmente três razões. Em primeiro lugar, a antecedência filo e ontogenética do oral; em segundo lugar, o fato de a leitura ter ocorrido em voz alta durante séculos, antes de passar para a leitura silenciosa; enfim, se concordamos sobre o fato de que não há linguagem sem entonação, então, é preciso concordar também sobre o fato de que a linguagem mental é dotada de entonação.

\section{II-1. Antecedência filo e ontogenética}

No que diz respeito à corrente fonográfica, tudo leva a crer que permanece, mesmo que diversamente, habitada pela questão da origem. Ora, nem a antecedência filogenética do oral em relação ao escrito (historicamente, o escrito apareceu depois do oral), nem sua antecedência ontogenética (assim, o homem adquire naturalmente a fala antes de ler e escrever, que são atividades que precisam de uma aprendizagem) constituem razões necessárias e suficientes para presumir, no plano sincrônico, a língua escrita como sendo um mero derivado da língua oral.

Limitar-me-ei, aqui, a apontar as razões que levam a descartar a representação segundo a qual a escrita seria uma representação do oral. Aliás, se fosse o caso, "o discurso escrito seria metalinguiístico e seria necessário passar pela expressão oral para ter acesso ao conteúdo do escrito", assim como o observa tão pertinentemente J. Rey-Debove (1988, p. 76). Por exemplo, não seriam possíveis os casos em que uma língua estrangeira, seja ela viva ou morta, se aprende meramente através do escrito (no ler e no escrever). Além disso, não há relação biunívoca entre palavra escrita e pronunciada. Com efeito, pelo fato de a escrita se realizar por meio de grafemas ordenados segundo a ortografia, seríamos levados a 
pressupor, caso a escrita fosse uma representação do oral, que existe somente uma pronúncia possível para cada palavra de uma determinada língua, o que contradiz a possibilidade de várias pronúncias concorrentes, bem como a pluralidade de sotaques, tanto endolíngues quanto exolíngues. A última razão que levantarei aqui é o fato de que o oral e o escrito, por ambos se manifestarem mediante a língua, diferem sobretudo quanto à expressão. Elaborada por Hjemslev, essa distinção remete aos planos da substância da expressão - o ar para o oral, a tinta para a escrita -, e da forma da expressão o fonema para o oral, o grafema para a escrita. A escrita tem como substância da expressão a tinta, o que implica uma superfície. A partir daí, é possível abordar a escrita, não mais numa dependência qualquer do oral, e sim como ligada a um modo de realização e de comunicação singulares, possibilitado por essa especificidade irredutível.

\section{II-2. A leitura em voz alta}

Pode-se perguntar, agora, se há uma relação entre a pontuação e o oral. Dizer que a pontuação indica as pausas (por exemplo, por meio da vírgula) e a entonação (por meio dos vários pontos) é uma postura comum, amplamente difundida entre os gramáticos (cf. Dahlet, 2002). A voz, através de suas principais características, reintegraria ou melhor, não teria deixado - o escrito via pontuação.

A função de pausa ligada à pontuação fazia plenamente sentido na época, remota, em que se lia em voz alta. Com efeito, o lugar da inspiração - que é silêncio, já que é somente no momento da expiração que podemos falar - era indicado pelo lugar do sinal de pontuação, que coincidia com um limite sintático-semântico. $\mathrm{O}$ mesmo ocorre ainda hoje, caso se leia em voz alta. No entanto, linguiistas mostraram que não existe um isomorfismo rigoroso entre pontuação e pausa, quando o texto é oralizado. 
Filol. lingüíst. port., n. 8, p. 287-314, 2006.

Isto posto, hoje em dia, a leitura silenciosa, ou seja, meramente visual, é praxe. ${ }^{7}$ Nesse contexto, como já vimos, a pontuação constitui um aparato de marcas visuais indicadoras de operações que guiam o tratamento da informação, operações que se dispensam do recurso ao oral.

\section{II-3. Oral, escrito, entonação, pontuação}

Expliquei, acima, a persistência da noção de pausa pelo fato de os gramáticos não terem questionado os pressupostos nela contida. Certamente, essa explicação não basta, e convém perguntar se essa persistência não resulta de uma intuição, desta vez, justa, mas cujas inferências, sob o efeito da tradição gramatical, estão erradas.

A intuição diz respeito, primeiramente, ao fato de que tanto o oral quanto o escrito precisam de algo que atribui posições aos elementos de um determinado enunciado [Doc.2]. O que J. Anis (1988, p. 154) resume e problematiza brilhantemente nos seguintes termos:

A solução mais razoável do problema da relação entre entonação e pontuação parece ser aproximá-las no plano de suas funções: cada uma delas, em seu domínio, é portadora de indicações sintáticas, temáticas e enunciativas; quando lemos um texto, decodificamos os topogramas [sinais de pontuação] e se oralizarmos, a partir das significações percebidas, utilizaremos marcas entonativas correspondentes. ${ }^{8}$

Ou seja, tanto a pontuação no escrito quanto a entonação no oral manejam as posições sintáticas num determinado enunciado.

Voltando à intuição dos gramáticos, direi, portanto, que ela é pertinente. A ambigüiidade, a não ser o erro, reside no fato de ex-

A alfabetização maciça, a familiarização com o número impressionante de escritos que nos cerca diariamente e, enfim, o aperfeiçoamento das técnicas de editoração, promoveram, creio eu, a mudança no modo de ler.

8 Útil, também, a precisão de Anis sobre a oralização: "durante muito tempo confundida com a leitura, [ela] é o simétrico da transcrição” (1988, p. 150). Oralizar pressupõe a leitura, mas a leitura não pressupõe a oralização. 
DAHLET, Véronique. A pontuação e as culturas da escrita.

pressá-la na perspectiva de dependência da escrita em relação com o oral, de tal modo que a função de grande parte dos sinais de pontuação é interpretada como tentando restituir os componentes do oral, além de construir a sintaxe.

Em segundo lugar, a intuição justa diz respeito ao fato de que não existe nem a possibilidade de expressão verbal se não houver entonação. É obvio para o oral, mas não deixa de valer também para o escrito. Citarei aqui Charles Bally (1951, p. 94):

\section{A entonação é o comentário perpetual da palavra, e por conseguinte do pensamento; ela acompanha a palavra interna bem como a linguagem arti- culada (...), o próprio pensamento comporta uma entonação, idêntica àquela das palavras pelas quais nos o expressaríamos. Do mesmo modo, não lemos mentalmente sem entonar aquilo que lemos.}

Não há enunciado senão entoado, ${ }^{9}$ diz A. Culioli. M. Já Bakthin dizia que a entonação é primeira condição de manifestação de qualquer objeto linguageiro (esquema 2) [Doc.3]. Trata-se, portanto, de um outro deslocamento em relação à representação comum, a saber: sendo a entonação o próprio do oral, a escrita não tem opção senão buscar recuperá-la, ainda que de maneira imperfeita e infiel (esquema 1) [Doc.3].

A entonação é uma só para cada língua, já que se trata de um componente sintático. Entre as realizações oral e escrita da língua, a linha de divisão diz respeito às posições sintáticas, elas mesmas decorrentes das posturas enunciativas e comunicativas do ato linguageiro que podem ora se encontrar, ora não, em ambas as modalidades, como bem demonstrou Marcuschi (2000).

Os três pontos de discussão aqui levantados, isto é, a antecedência filo e ontogenética, a leitura em voz alta e a função similar

9 “Il n’y a d'énoncé qu'intoné”, diz Culioli num seminário ministrado em 1984. Cf. também M. Bakhtine: "Les frontières entre poétique et linguistique", in Todorov (1981), sobre a primazia da entonação, e V. Dahlet "A entonação no dialogismo bakhtiniano", in B. Brait (Org.) (1997). 
de construção sintática da entonação no oral e da pontuação no escrito respectivamente, mostram claramente a persistência, no imaginário coletivo e, no nosso caso, dos gramáticos, em pôr, de maneira incondicional, a voz - nas suas realizações fônicas e nas suas recepções acústicas - como origem absoluta do todo. Não estamos longe, aqui, dos mitos de criação do mundo que, além de suas diferenças formais remetentes às várias regiões do planeta, convergem ao presentear a voz - i.e., respiração, música e espírito - como fenômeno que desencadeou a criação do mundo.

Voltando à persistência dos estudiosos da pontuação em pôr, como preestabelecido, a voz até mesmo na escrita, gostaria de enfatizar o paradoxo dessa postura teórica, que vem se mantendo apesar da longa e persistente reflexão e conceituação do branco como suporte e superfície tornada apta a receber um sentido, cuja virtude, até então jamais alcançada, consistiu em se elaborar, não mais como espelho do mundo e sim como construção de uma operação mental.

\section{O BRANCO, APESAR DA VOZ \\ III-1. Os sianis que valem pela voz}

Na conceituação da pontuação, surgiu um código específico, apto a encenar a palavra falada, a representar o falado pelo escrito. Ou seja, tratava-se de refazer o percurso "inverso" às representações majoritárias, ao inserir a imagem da voz na escrita, através de um dispositivo tipográfico complexo, que representou, para os tipógrafos, um desafio.

Chamei esse dispositivo de sinais de conduta de diálogo (Dahlet, 2006) [Doc. 4]. Ele se compõe:

i. do dispositivo tipográfico de formalização do diálogo, ou seja, o travessão, bem como a frequiente translineação, as aspas e as reticências de interrupção; 
DAHLET, Véronique. A pontuação e as culturas da escrita.

ii. dos sinais que assumiram a função convencional de remeter, por conotação, a certas modalidades de uma voz falada jamais ocorrida: intensidade da voz (maiúscula contínua), mudança de altura (itálico), entonação (pontos de exclamação e de interrogação), fluxo (reticências de fluxo). ${ }^{10}$

Todos esses sinais se apresentam como representações gráficas de discursos orais (que estes sejam fictícios ou transcritos não tem nenhuma importância) e, a esse título, atribuímos-lhes imediatamente o valor de uma representação qualificante da voz: os sinais valem pela voz.

Ora, representar o falado pelo escrito, apesar de muito frequiente e, por isso mesmo, parecendo "natural", não deixa de ser paradoxal. Com efeito, o sinal de pontuação é, com a disposição na página, o que há de mais escrito (lembremos que ele não possui correspondência fonemática). Vimos que a entonação do oral e uma certa pontuação do escrito preenchem, cada qual em seu domínio, funções sintático-semânticas similares. Ora, o cotexto dialogal escrito modifica essa bipartição, pela representação de um diálogo oral transcrito, que obriga o leitor a "ouvir" a entonação das vozes representadas. Trata-se de uma codificação que, por um efeito de ilusão, leva o canal escrito para um exterior a ele mesmo, sem que isso, contudo, se realize: mimesis de um falado e, portanto, de uma entonação e de um fluxo, dos quais se pressupõe, por convenção, que se tenham efetivamente realizado.

O que diferencia esses sinais de pontuação, que operam em cotexto monologal ou dialogal?

10 Não voltarei mais a certos valores das reticências, analisados em cotexto monologal e que podem, evidentemente, encontrar-se na fala de personagem. Nesse caso, a única diferença, lembremos, diz respeito ao estatuto do leitor, que se encontra aqui excluído, ali, implicado (cf. Dahlet, 2006). 
Filol. lingüíst. port., n. 8, p. 287-314, 2006.

i. a responsabilidade pragmática se desloca entre os parceiros do diálogo representado (grosso modo, entre os personagens citados), ao passo que, em cotexto monologal, o diálogo envolve o leitor e o escriptor. Sem dúvida, é igualmente por essa razão (a saber, que o leitor de um diálogo romanesco é um terceiro excluído, ao passo que o leitor do escrito comum é um interlocutor, logo, por definição, incluído) que

ii. eles são incrementados com um valor qualificante da voz, como se a fala representada se confundisse com uma transcrição.

\section{III-2. Representar a interjeição e o riso por escrito}

A representação da interjeição e do riso pelo escrito constituem o extremo das experimentações da escrita, pois chegamos na ponta avançada do paradoxo, isto é, a interjeição e o riso revertidos em escrita, e quase obrigatoriamente seguidos do ponto de exclamação. Por serem desprovidos de articulação linguageira, constituem as duas manifestações mais claras da mimesis construída a partir de um modelo do oral. Se a exclamação é interpretada como "'tendo escapado' a seu autor" (Ducrot, 1984, p. 186), ainda mais a interjeição, que pertence por natureza à interação face a face e se caracteriza como um "elemento reativo" (Barbéris, 1995, p. 95). E podemos ver que o riso escrito concentra todas as características da interjeição, porém, num grau superior, por assim dizer. O riso não aparece mais como "escapado", mas como "arrancado" pelo irresistível da situação: ele é reativo, já que é em princípio pura vocalização. É por isso que foi preciso atribuir ao riso formas grafêmicas, distribuídas em função do sentido do mesmo. Assim, ah ah ah! evoca o riso aberto, hi hi hi o riso contido ou constrangido, hé hé hé! o riso insidioso, ho ho ho! o riso zombeteiro, e, nesse ponto, a transcrição do riso fica bastante próxima da onomatopéia. 
DAHLET, Véronique. A pontuação e as culturas da escrita.

Esse percurso intitulado "O branco apesar da voz" pretendeu mostrar, mediante a escrita do falado, da interjeição e do riso, o trabalho de conceituação para elaborar um dispositivo de sinais de pontuação capazes de formalizar a representação acústica da voz (articulada e não articulada) na escrita. Percebemos, assim, dois momentos contraditórios, apesar de simultâneos. Pois, ao mesmo tempo em que reina a concepção da pontuação como portadora da voz (e aqui cabe perguntar de quem seria a voz em questão), existe um longo trabalho de elaboração de um dispositivo pontuacional e tipográfico para formalizar a representação da voz, demonstrando claramente que a voz como emissão vocal não tem residência na escrita.

\section{POEMAS TIPOGRÁFICOS E ROMANCES SONOROS}

O outro movimento paradoxal que gostaria de analisar remete, mais uma vez, a duas tendências contrárias. Uma se desenvolveu na poesia, a outra, algumas décadas mais tarde, na prosa romanesca. Ambas questionaram representações cuidadosamente construídas ao longo dos séculos, derrubando as fronteiras que separavam a poesia da prosa, a prosa da poesia. Essas representações dizem respeito sobretudo à associação da poesia com a musicalidade, mediante as rimas, as aliterações, as assonâncias e o ritmo, ao passo que a prosa romanesca era confinada à transposição do real, quando não à sua restituição. Ora, já na véspera do século $\mathrm{XX}$, a poesia se desloca para o visual, para a materialidade de sua inscrição na página, ao passo que, mais tarde, foi a vez do romance de visar a uma escritura feita para ser ouvida.

\section{N-1. Poesia: retração da pontuação, avanço do branco}

Quatro séculos depois da invenção do códice, que acarretou a noção de página, a publicação em 1897 de Un coup de dés..., de Stéphane Mallarmé, suscitou a estupefação geral por ter mudado a escala da 
unidade visual/escritural da página. A elevação dessa unidade-padrão para a superfície total do papel quando o volume do livro está aberto bastou para quebrar a linearidade tanto da escrita - criando constelações, no próprio dizer de Mallarmé - quanto da leitura, multiorientada, tabular. ${ }^{11}$ Como o observa A. M Christin (2000, p. 168), ao revolucionar a expressão poética, a ousadia impensável de Un coup de dés... consistiu em espantar a própria concepção que "a civilização do alfabeto se tinha elaborado, desde séculos, da comunicação escrita”. De fato, Mallarmé foi (ainda no dizer de Christin 2000:183-184), "o primeiro a ter utilizado os recursos do espaço tipográfico como uma verdadeira "língua escrita". O vazio, o branco, é promovido à função de sintaxe. Por isso, as palavras em forma de constelações prescindem dos sinais de pontuação, pelo menos tais como listados nas gramáticas, já que, como pudemos ver, considero os itálicos, o negrito, assim como a maiúscula contínua sinais de pontuação enunciativos.

Em poesia, as criações que dizem respeito à exploração criativa do branco da página levaram todas elas a uma retração, quando não à simples desaparição da pontuação. Pensemos no primeiro poema desprovido de pontuação, de Guillaume Apollinaire, assim como os Caligramas (1918). O caligrama é uma palavra formada da junção de caligrafia e de ideograma, o que aproximou poesia da pintura. Apollinaire colocará como epígrafe aos seus Caligramas: "E eu também sou um pintor".

Ou seja, esse período corresponde, no tocante à poesia, à passagem do ler ao ver. A poesia se torna quadro, na medida em que a escrita poética fundamenta seu modo de geração na espacialidade de sua inscrição. Na virada do século XX, a poesia visual, tipográfica, tem como nome Maiakovski (1913), que reivindica o

11 Não é o lugar, aqui, de indagar a relação entre a biface página/unidade e a tela, de cujas janelas e inúmeros links recriam, na verdade, o sentimento de volume (identificando-se nesse aspecto com o livro), sem, entretanto, manter a ordem progressiva ou regressiva das páginas de livro. Pelo contrário, as janelas e os links recriam um percurso à maneira de constelação. 
DAHLET, Véronique. A pontuação e as culturas da escrita.

direito do poeta de atribuir um sentido às palavras em função de seu caráter gráfico e fônico; tem como nome o futurismo lançado por Marinetti através de seu Manifesto (1913), tem como nome Tristan Zara, que funda na cidade de Zurique o dadaísmo em $1916 .{ }^{12}$

A poesia tipográfica se afasta da declamação; ela faz retrair até a possibilidade de oralização, inclusive, portanto, a linguagem mental. Em outras palavras, o poema se torna estrutura visual significante somente sob a condição de que o olhar do leitor-espectador se desloca nele, movimentando a circulação do sentido.

Curiosamente, portanto, a poesia visual se concebe na mudez: o que autoriza, por exemplo, o constructivista russo Lissitsky (apud Daniel Renoult, 1991, p. 405) a declarar aos críticos:

A forma tipográfica deve (...) realizar mediante os meios óticos que lhe são próprios, aquilo que a voz e o gesto de um orador realizam em prol de suas idéias.

Esse divórcio entre o visual e o auditivo é chamado pelo poeticista Henri Meschonnic de intratipografia, definida por ele como um "conjunto de efeitos essencialmente procedentes do visual, praticando um dualismo do visual e do auditivo de modo a torná-los desoralizados: inaudíveis na maioria dos casos" (1982, p. 309). Assim, a primazia do tipográfico fazendo da letra-palavra um corpo e da página um espaço, aliada à desarticulação da sintaxe e da linearidade, esvaziou a pontuação de qualquer função, tornando-a de fato dispensável.

Envolvendo os dois lados do Atlântico, a poesia visual das primeiras décadas do século XX, "intratipográfica", desfez o imaginário ocidental velho de milhares de anos, que fundamentava a superioridade da poesia sobre a prosa pelo seu poder de totalização, de completude, pela sua "linguagem completa" no dizer de Paul Valéry, na sua "Théorie poétique et esthétique" (1957, p. 1336). Segundo Valéry, a "linguagem completa" que constitui o próprio da

12 Ver também Reverdy (poemas-quadros); Ezra Pound (Cantos), etc. 
poesia é uma "linguagem cuja forma, isto é, a ação e a sensação da Voz, é de igual potência que o fundo".

Na realidade, o critério maior que permitia, para os críticos do século XIX, distinguir a poesia da prosa era justamente o objetivo, para que a poesia se legitimasse como tal, de constantemente pressionar a forma, mediante a "ação e a sensação da Voz" que, como veremos, emerge do ritmo. Assim, enquanto a escrita em poesia era apreendida como matéria verbal a trabalhar, depurar, para aproximar-se de sua quintessência - o que, de certo modo, reativa o arquétipo da poesia como linguagem dos deuses - atribuía-se à escrita romanesca a função de revelar uma (pseudo) realidade que lhe seria ao mesmo tempo anterior e externa. Cabe salientar que o fato de conceder um estilo ao romancista não invalida, nem tampouco fragiliza, a concepção de uma escrita como ferramenta suscetível de alcançar o real.

\section{N-2. ROMANCE: RETRAÇÃO DA PONTUAÇÃO, AVANÇO DAVOZ,}

\section{N-2. 1. Poesia, prosa, ritmo}

Mallarmé declarou, numa enquête intitulada "Sobre a evolução literária” (1945, p. 867), algo impensável:

\footnotetext{
O verso está em todo lugar na língua onde há ritmo (...). No gênero chamado prosa, existe versos, às vezes admiráveis, de todos ritmos. Mas, na realidade, não existe prosa: existe o alfabeto e versos mais ou menos concentrados: mais ou menos difusos.
}

A noção-chave que propiciou esse deslocamento conceitual e até epistemológico é a noção de ritmo, doravante não mais circunscrita exclusivamente à poesia. Ao retomar a evolução semântica da palavra ritmo, Benveniste observa que o ritmo não se relaciona, etimologicamente, com a noção de cadência, de periodicidade regular (como, por exemplo, o ritmo das ondas, o ritmo das maresias ou o ritmo cardíaco). Pelo contrário, trata-se de uma maneira de 
DAHLET, Véronique. A pontuação e as culturas da escrita.

dispor as coisas, de um arranjo, que não é fixo. Cito ele (1966, p. 332-3):

[a palavra grega] designa a forma desde que assumida por aquilo que é movediço, móvel, fluido, a forma daquilo que não tem forma orgânica.

Assim, portanto, o ritmo remete ao fluir. Essa renovação na abordagem da noção do ritmo desencadeou estudos extremamente instigantes, entre os quais o de Henri Meschonnic, que, na sua Critique du rythme (1982a), desenvolve um aparato teórico inovador. Com efeito, apoiando-se na concepção do ritmo como um "modo de significar", o estudioso situa o ritmo no discurso, não do lado do sentido, e sim do lado da significância, pois o ritmo, pela sua mobilidade, pelo seu fluir, dá o impulso ao discurso e exprime mais do que o sentido (sentido definido aqui como superfície discursiva estruturada, que remete às estruturas de um exterior). Meschonnic criou o conceito de oralidade para dar conta da significância que, junto com o sentido, faz a totalidade texto. A oralidade, que é "a poética da voz" (1989, p. 264), estabelece (1982b,p. 18) a

primazia do ritmo e da prosódia no semântico, em certos modos de significar, escritos ou falados (...). Uma semântica da significância generalizada, contínua no descontínuo das unidades discretas, onde se limita a semântica do signo [linguiístico].

Assim, a noção de oralidade nos interessa em primeiro lugar porque ela subsume a dicotomia do oral e do escrito, pois a oralidade pode se desenvolver, ou não, tanto no oral quanto no escrito; em segundo lugar, ela nos interessa por ter a característica de se desenvolver ou não no próprio escrito, e esse fato permite entender as razões pelas quais um poema pode ser desprovido de qualquer densidade poética, ao passo que um texto em prosa - poema ou romance - pode ser investido de um alto grau de poeticidade.

Se concordarmos, por um lado, com Mallarmé, cuja visão parte do alfabeto para chegar a uma linguagem cuja densidade, além ou aquém da dicotomia prosa/poesia, se avalia em função do ritmo; se, 
por outro lado, concordamos com Paul Valéry que identifica a poesia à linguagem completa, isto é, quando a "sensação da Voz" é tão pregnante quanto o conteúdo temático, então, é possível dizer que a escrita romanesca pode alcançar um alto grau de poesia. É isso que vou tentar demonstrar agora, apoiando-me numa literatura que, por criar sua estética mediante a tensão contínua da significância, é uma literatura que pede para ser, no processo de leitura, ouvida.

\section{N-2.2 Uma literatura para ser ouvida}

Aportamos, mais uma vez, a um paradoxo: uma literatura para ser ouvida. Entretanto, já vimos que a "oralidade" (no sentido de Meschonnic), isto é, a significância, "a Voz em ação", no dizer de Paul Valéry, que a define como sendo "os caracteres sensíveis da linguagem, o som, o ritmo, os acentos, o timbre, o movimento" (1957, p. 1332), constitui a matéria trabalhada para a escrita ser ouvida.

A hipótese é formulada da seguinte maneira: sendo a significância colocada no mesmo patamar que os conteúdos temáticos, a criação que permite que a "Voz" entre em ação - para parafrasear Valéry reside, em primeira e última instância, no fazer da pontuação, com os sinais de conduta de diálogo, em primeiro plano.

No seu artigo "Guillemets et marques du discours direct", Roger Laufer (1977, p. 55) diz com muita pertinência que:

\section{A tipografia afetou não somente o estilo, mas também as condições a priori da comunicação. Eu considero certeza absoluta o fato de que o enunciado romanesco com várias vozes do século XIX não poderia ter existido sem o novo sistema tipográfico, baseado na alínea, no travessão e nas aspas (...).}

Ora, no exato momento em que os tipógrafos se esforçavam para formalizar e racionalizar o sistema de citação das vozes de personagens, os romancistas já estavam a alargar/recuar os limites estabelecidos pelo próprio sistema. Podemos citar de antemão o estilo indireto livre, que constrói "a fusão de dois pontos de vista, ou de duas 'vozes”, o que leva Ann Banfield, em Phrases sans paroles 
(1982, p. 280) a avançar a teoria da "dupla voz". Do ponto de vista da estética literária, a fusão de duas vozes provoca o remanejamento, ou uma certa opacificação, da estrutura acentual da língua envolvida - já que a fusão gera uma indeterminação, de duração variada, no que diz respeito às fronteiras sintagmáticas, nesse caso divisoras das vozes, enquanto se sabe que são justamente as fronteiras sintagmáticas que, na linearidade da escrita, organizam os grupos acentuais, os quais participam da configuração geral do ritmo.

Num plano por assim dizer mais avançado, no sentido de que o ritmo e a significância se manifestam constantemente à flor da escrita, evocarei o monólogo interior. Temos todos em mente o monólogo de Molly, no último capítulo, "Penelope", de Ulisses, de James Joyce. O monólogo é escrito e lido sem sinal de pontuação, exceto a alínea que decompõe a enunciação em "nove frases". Ora, lembrando que a pontuação tem como função primeira a de auxiliar a leitura pela legibilidade otimal, o leitor de um texto sem sinais retrograde, por assim dizer, a um estado de explorador ou de principiante, já que entra num espaço tornado desconhecido, não podendo mais apoiar-se sobre seus reflexos, transmitidos pela pontuação, de decomposição/hierarquização dos segmentos sintático-semânticos. Enquanto isso, no intuito de suprir a falta de pontuação, o leitor é levado a se concentrar, muito mais que em textos com pontuação, nos elementos que componham a significância, isto é, "a Voz em ação": ritmo, acentos, timbres (Valéry) e, ainda, movimento (Meschonnic). Quando se trata de monólogo interior, é comum falar de "fluxo do pensamento". ${ }^{13}$ Pelo fato de o monólogo interior não somente ficar liberado de qualquer controle social e de qualquer enquadramento pragmático-discursivo, como, também, por criar uma dimensão temporal única em que há uma isocronia absoluta (Genette, 1972, p. 122-3) entre o tempo e a história, já que "a única indicação, no texto, do decorrer do tempo é a sucessão

13 Talvez não seja inútil observar que a expressão fluxo do pensamento, no contexto do monólogo interior, não tem relação nenhuma com a expressão utilizada pelos gramáticos quando tentam explicar a função das reticências! 
das palavras na página” (Dorrit Cohn, 1978, p. 248), o monólogo interior é o lugar por excelência da "desagregação das subjetividades". Assim, esse fluxo, que por ser desconectado do terceiro social, aborda, linguiisticamente falando, as margens da loucura. Reviravolta ou pulverização dos conteúdos temáticos que entram em choque pela rarefação da pontuação, a qual até certo ponto deixa a sintaxe à deriva; ausência da pontuação de conduta de diálogo (cf. Doc.4) quando o personagem, no seu monólogo, retoma falas de outros personagens, criando assim uma dinâmica de antropofagia das falas, já que elas mesmas atraem comentários do próprio personagem ou de outros, por sua vez novamente inseridos no monólogo. Cabe, portanto, ao leitor, cativado pela "Voz em ação", tal qual Ulisses pelo canto das sereias, costurar o melhor possível, pelo jogo da sua própria subjetividade, os rasgos das subjetividades literariamente representadas.

\section{CONCLUSÃO}

Finalizando este estudo, direi que tentei apontar as etapas a meu ver mais significativas, porque portadoras de rupturas, onde foi possível identificar a interação entre pontuação e escrita, ambas constituindo espaços de legibilidade, de conquista de saber e de criação literária. Nessa apresentação, tentei também mostrar que essas etapas foram acompanhadas de movimentos de fundo, que desembocam muitas vezes em paradoxos. Mas talvez seja próprio do pensamento humano progredir com a dinâmica desses últimos. 
DAHLET, Véronique. A pontuação e as culturas da escrita.

ANEXOS

\section{DOCUMENTO 1 - SINAIS DE SEQÜENCIALIZAÇÃO E SINAIS DE ENUNCIAÇÃO}

I. CORPUS DOS SINAIS DE SEQÜENCIALIZAÇÃO: SEGMENTAÇÃO DA LINEARIDADE

- alínea

- ponto

(e seus derivados: pontos de interrogação, de exclamação e reticências)

- ponto-e-vírgula

- vírgula

II. CORPUS DOS SINAIS DE ENUNCIAÇÃO E FUNÇÕES

\begin{tabular}{|c|c|c|}
\hline & $\begin{array}{l}\text { cotexto monologal } \\
\end{array}$ & cotexto dialogal \\
\hline $\begin{array}{l}\text { 1. hierarquizadores } \\
\text { discursivos }\end{array}$ & $\begin{array}{l}\text { - dois-pontos } \\
\text { - travessão (duplo) } \\
\text { - parênteses }\end{array}$ & \\
\hline $\begin{array}{l}2 . \text { indicadores } \\
\text { referenciais }\end{array}$ & $\begin{array}{l}\text { - aspas autonímicas } \\
\text { - aspas de conotação autonímica }\end{array}$ & \\
\hline 3. sinais de citação & & $\begin{array}{l}\text { - aspas } \\
\text { - itálico } \\
\text { - colchetes }\end{array}$ \\
\hline $\begin{array}{l}\text { 4. marcadores } \\
\text { expressivos }\end{array}$ & $\begin{array}{l}\text { - itálico } \\
\text { - maiúscula contínua } \\
\text { - negrito } \\
\text { - travessão }\end{array}$ & \\
\hline $\begin{array}{l}\text { 5. marcadores } \\
\text { de interação }\end{array}$ & $\begin{array}{l}\text { - ponto de interrogação } \\
\text { - ponto de exclamação } \\
\text { - reticências }\end{array}$ & \\
\hline $\begin{array}{l}\text { 6. sinais de conduta de } \\
\text { diálogo }\end{array}$ & & $\begin{array}{l}\text { - maiúscula contínua } \\
\text { - itálico } \\
\text { - ponto de interrogação } \\
\text { - ponto de exclamação } \\
\text { - reticências de fluxo } \\
\text { - reticências de } \\
\text { interrupção } \\
\text { - travessão de diálogo }\end{array}$ \\
\hline
\end{tabular}

Réf.: V. Dahlet (2006).

310 
Filol. lingüíst. port., n. 8, p. 287-314, 2006.

DOCUMENTO 2 - ENTONAÇÃO E SINTAXE

\begin{tabular}{|l|l|}
\hline & \multicolumn{1}{|c|}{ oral } \\
\hline (a.1) & (b.1) Não podem atirar. \\
(a.2) $\quad$ [ não pod? atirar $]$ & (b.2) Não, podem atirar. \\
\hline
\end{tabular}

\section{DOCUMENTO 3 - ENTONAÇÃO, ORAL E ESCRITA}

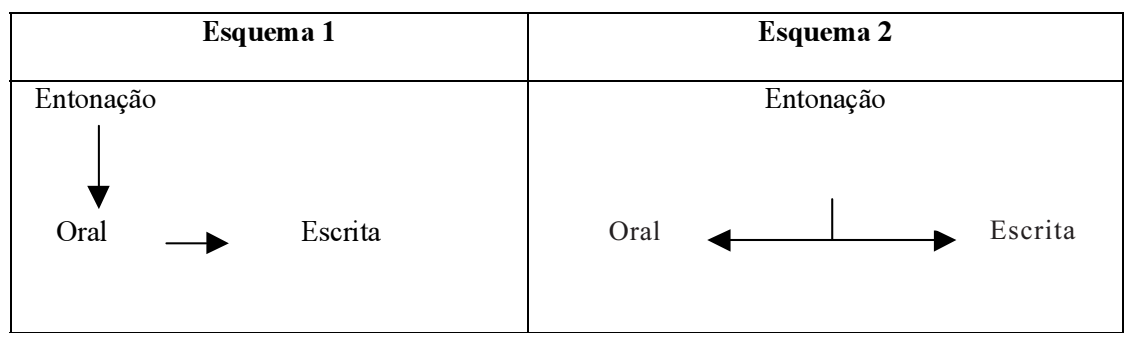

\section{DOCUMENTO 4 - SINAIS DE CONDUTA DE DIÁLOGO}

- letra de forma

- itálico

- capital

- ponto de interrogação

- ponto de exclamação

- reticências de fluxo ${ }^{14}$

14 As reticências de fluxo dizem respeito às que indicam o fato do personagem interromper, de maneira provisória ou definitiva, sua própria fala. Por isso, chamamos essa interrupção de "homo-interrupção". Em contrapartida, as reticências de interrupção remetem ao fato de um personagem interromper a fala de um outro. Nesse caso, há troca de fala: chamamos essas reticências de "hetero-interrupção". 
DAHLET, Véronique. A pontuação e as culturas da escrita.

\section{- reticências de interrupção \\ - travessão de diálogo}

\section{BIBLIOGRAFIA}

ANIS, Jacques [Chiss Jean.-Louis. \& Puech Christian, Collab.] (1988). L'écriture. Théories et descriptions. Bruxelles: De Boeck/Université.

ARABAYAN, Marc (1994). Le paragraphe narratif. Paris: L'Harmattan.

ARAÚJO, Emanuel (1986). A construção do livro. Rio de Janeiro: Nova Fronteira.

BAKHTINE, Mikhail (1981). "Les frontières entre poétique et linguistique“. In: TODOROV, Tzvetan (1981). Mikhaïl Bakhtine. Le principe dialogique Suivi de Écrits du Cercle de Bakhtine. Paris: Seuil, Poétique.

BALLY, Charles (1951). Traité de stylistique française. 3. ed., t.1. Paris: Klincksieck.

BANFIELD, Ann (1982). Phrases sans parole. Théorie du récit et du style indirect libre [1995 trad.]. Paris: Seuil.

BENVENISTE, Émile (1966). "La notion de 'rythme' dans son expression linguistique". Problèmes de linguistique générale. T.1. Paris: Gallimard, Tel.

BOTTÉRO, Jean (1987). "A escrita e a formação da inteligênica na Mesopotâmia Antiga”. In: BOTTÉRO, Jean; MORRISON, Ken et al. [1995 trad.]. Cultura, pensamento e escrita. São Paulo: Ática.

CHARTIER, Roger (1996). Culture écrite et société. Paris: Albin Michel, Histoire.

CHATILLON, Jean (1985). "Désarticulation et restructuration des textes à l'époque scolastique". In: ROGER, Laufer (1985). La notion de paragraphe. Paris: CNRS.

CHRISTIN, Anne-Marie (2000). Poétique du blanc. Vide et intervalle dans la civilisation de l'alphabet. Leuven, Peeters/Vrin.

. (2001). L'image écrite ou la déraison écrite. [1 $1^{\mathrm{a}}$ ed. 1995] Paris: Flammarion, Champs.

COHN, Dorrit (1978). La transparence intérieure. Modes de représentation de la vie psychique dans le roman [1981 trad.]. Paris: Seuil, Coll. Poétique.

DAHLET, Véronique (1997). "A entonação no dialogismo bakhtiniano”. In: BRAIT, Beth (Org.). Bakhtin, dialogismo e construção do sentido. Campinas: Ed. Unicamp.

. (2002). "A pontuação e sua metalinguagem gramatical". Revista de Estudos da Linguagem. Belo Horizonte: FALE/UFMG, v. 10, n.1.

. (2006). As (man)obras da pontuação. São Paulo: Editora Humanitas/FFLCH e Fapesp.

GENETTE, Gérard (1972) Figures III. Paris: Seuil, Coll. Poétique.

GOODY, Jack (1993). Entre l'oralité et l'écriture [1994 trad.] Paris: PUF.

ILLICH, Ivan (1991) Du lisible au visible. Sur l'art de lire de Hugues de Saint-Victor. [1991 trad.]. Paris: Les Editions du Cerf.

312 
Filol. lingüíst. port., n. 8, p. 287-314, 2006.

JACOB, Christian (1996). "Ler para escrever: navegações alexandrinas". In: MARC, Baratin \& Christian Jacob Dir. [2000 trad.]. 0 poder das bibliotecas. A memória dos livros no Ocidente. Rio de Janeiro: Ed. UFRJ.

LAUFER, Roger (1977) “Guillemets et marques du discours direct”. La ponctuation. Recherches historiques et actuelles. T.2 . Paris-Besançon: CNRS/Groupement de recherche sur les Textes Modernes.

. (1985) "L'alinéa typographique du XVI e siècle au XVIII ${ }^{\mathrm{e}}$ siècle". La notion de paragraphe. Paris: CNRS.

GENETTE, Gérard (1972). Figures III. Paris: Seuil, Coll. Poétique.

GOODY, Jack (1993). Entre l'oralité et l'écriture [1994 trad.]. Paris: PUF.

MALLARMÉ, Stéphane (1945), “Un coup de dés...”. Oeuvres Complètes. Paris: Gallimard, NRF, La Pléiade.

. (1945). "Sur l'évolution littéraire“. Oeuvres Complètes. Paris: Gallimard, NRF, La Pléiade.

MARCUSCHI, Luiz Antonio (2000). Da fala para a escrita. Atividades de retextualização. São Paulo: Cortez.

MESCHONNIC, Henri (1982a). Critique du rythme. Anthropologie historique du langage. Paris: Verdier. dezembro.

(1982.b) “Qu'entendez-vous par oralité?”. Langue Française 56. Paris: Larousse,

(1989). La rime et la vie. Paris : Verdier.

MORRISON, Ken (1987). "Estabelecendo o texto: a institucionalização do conhecimento por meio das formas históricas e filosóficas de argumentação", in Bottéro Jean, Morrison Ken e alii [1995 trad.]. Cultura, pensamento e escrita. São Paulo: Ática.

REY-DEBOVE, Josette (1988). “À procura da distinção oral/escrito”. In: CATACH, Nina (Org.). Para uma teoria da língua escrita [1996 trad.]. São Paulo: Ática, Coleção Múltiplas Escritas.

SOUCHIER, Emmanüel (1999). "Histoires de pages et pages d'histoire". In: ZALI, Anne (Dir.) (1999). L'Aventure des écritures. La page. Paris: Bibliothèque nationale de France.

VALÉRY, Paul (1957). "Théorie poétique et esthétique”“. Oeuvres. T.1. Paris: Gallimard, NRF, La Pléiade.

ZALI, Anne (1999) "La page du rouleau égyptien, une architecture rigoureuse". In: ZALI, Anne (Dir.) (1999). L'Aventure des écritures. La page. Paris: Bibliothèque nationale de France.

RÉSUMÉ: Cette contribution cherche a montrer comment la page, quand elle a reussi a renvoyer a elle-meme en se constituant comme support et espace de l'secrit, a affranchi la pensee de la perception immediate du monde, affranchissement qui lui a permis de mettre au point ses propres techniques de scription, devenues auto-suffisantes. Cette profonde transformation s'est produite grace au perfectionnement des processus materiels de presentation de l'ecrit, et notoirement a travers la segmentation en paragraphes et la ponctuation. Cependant, on observe un paradoxe permament, lequel consiste a reconnaitre la surface concrete de la page, c'est 
DAHLET, Véronique. A pontuação e as culturas da escrita.

a dire le blanc, sans pour autant renoncer a associer la parole ecrite a la voix, qui serait portee principalement par les signes de ponctuation.

MOTS-CLÉS: Ponctuation; Paragraphe; Le blanc de la page; Voix; Culture(s) de l'écrit. 